Journal of Mathematics and Informatics

Vol. 12, 2018, 89-101

ISSN: 2349-0632 (P), 2349-0640 (online)

Published 21 March 2018

www. researchmathsci.org

DOI: http://dx.doi.org/10.22457/jmi.v12a9

Journal of

Mathematics and

Informatics

\title{
Effects of Negative Emotions on the Perceived Helpfulness of Online Reviews
}

\author{
Zhu Liu ${ }^{1}$, Jing Liu ${ }^{2}$ and Shuang Hao ${ }^{3}$ \\ ${ }^{1}$ School of Economics and Management \\ Chongqing University of Posts and Telecommunications \\ Chongqing, China. E-mail: liuzhu903@163.com \\ ${ }^{2}$ Chongqing Medical and Pharmaceutical College \\ Chongqing, China. E-mail: 717139038@qq.com \\ ${ }^{3}$ School of Economics and Management \\ Chongqing University of Posts and Telecommunications \\ Chongqing, China. E-mail: 499417014@qq.com \\ ${ }^{2}$ Corresponding author \\ Received 5 March 2018; accepted 20 March 2018
}

\begin{abstract}
Due to the popularity of online shopping, consumers increasingly rely on online reviews to make purchase decisions. Based on the theory of emotional cognitive evaluation, a theoretical model of the relationship between negative emotion and perceived helpfulness is constructed. The effects of negative emotions (anger, worry etc.) on the perceived helpfulness of online reviews are tested by experimental methods. The study found that certainty of expression and cognitive effort play an intermediary role in the effects of emotions on the helpfulness of online reviews. Meanwhile, the consumerperceived emotion 'worry' is more helpful than 'anger' in negative reviews.
\end{abstract}

Keywords: Negative emotions; online reviews; perceived helpfulness; emotional cognitive evaluation theory

\section{AMS Mathematics Subject Classification (2010): 97Q30}

\section{Introduction}

Online reviews play a very important role in e-commerce. According to survey conducted by CNNIC (2015), 77.5\% of Internet consumers believed Internet word of mouth was the most important factor in their decision making [1]. By browsing online reviews, consumers can improve decision-making efficiency and reduce the risk of product or service uncertainty [2]. However, in the era of "universal online shopping", consumers are faced with a huge amount of review information which breeds information overload [3]. Massive reviews information makes consumers impossible to quickly and efficiently identify valuable information when making purchasing decisions. Therefore, identifying useful information in online reviews quickly and effectively is important to improve customer decision-making efficiency and reduce the overall shopping costs.

Negative word of mouth had more influence on consumers than positive word of mouth [4]. Ahluwalia et al confirmed that consumers were more likely to notice negative 


\section{Zhu Liu, Jing Liu and Shuang Hao}

information [5]. Verhagen, Nauta and Feldberg showed that consumers generally shared real negative shopping experience [6]. Some scholars pointed out that the emotion expressed in the negative online reviews would be more easily perceived by consumers [7], which could help consumers judge the quality of products or services. Different negative reviews include different negative emotions of consumers, and there were great differences in the intensity of negative emotions, which make consumers' perception of such reviews different. Therefore, negative emotions deserve attention as an important factor in determining the perceived helpfulness of negative online reviews.

Basing on the theory of emotional cognition evaluation, we use experimental method to explore the effects of negative emotions on the perceived helpfulness and the intermediary role of online reviews of certainty of expression and cognitive effort.

\section{Research review}

\subsection{Emotions}

Consumption emotions were emotional experience of consumers after shopping. In the past two decades, there have been many studies on consumption emotions. The relationship between consumption emotions and post-purchase behavior has always been one of the key research directions for researchers $[8,9]$. Someone pointed out that if the potential consumers agreed with the emotions expressed by the reviewers in the online reviews, then the reviews were considered helpful [10], because consumers' perceived helpfulness of online reviews stemmed from the recognition of emotions in those reviews [11]. Some domestic scholars also pointed out that consumers who experienced certainty (such as happy and disgust) emotions and uncertainty emotions (such as surprise and fear) had different ways of choosing [12]. Most of the above researches focused on the relationship between consumption emotions and consumer satisfaction, repurchasing intention and oral communication behavior; but the relationship between consumption emotions and perceived helpfulness of online reviews was seldom concerned.

\subsection{Perceived helpfulness}

Perceived helpfulness was a reflection of consumers' subjective perception of online reviews. The existing researches on the perceived helpfulness of online reviews focused on the following three categories: first, the online reviews features, such as online reviews rating, online reviews valence (positive and negative reviews), the number of online reviews, the quality of online reviews, reviews content and so on [13,14], second, reviewer's characteristics, such as reviewer's professionalism, reviewer's credibility, reviewer's preferences and so on $[15,16]$, third, review reader characteristics, such as readers online shopping experience, the degree of understanding of the product, gender and so on[17,18].

The deficiencies of existing research include two aspects. First, shopping situations in existing researches were mainly in the foreign shopping situations, such as Ahmad and Laroche. Under the Chinese shopping situations, there is a lack of relevant research on the relationship between specific emotions and perceived helpfulness. Second, the existing researches explained the relationship between emotions and perceived helpfulness by a single intermediary variable. So, to a certain extent, our research can make up for these shortcomings. 
Effects of Negative Emotions on the Perceived Helpfulness of Online Reviews

\section{Theoretical basis and research hypothesis}

\subsection{Theoretical basis}

The theoretical basis of this article is the theory of emotional cognitive evaluation. The theory links cognition to human emotions [20], and considers emotion as the result of human evaluation of specific events or environment [21]. Each emotion had its own unique cognitive evaluation system that composed of a series of evaluation dimensions, so the differences between different emotions could be reflected [22], For example, consumers reviewed that the quality of the products which they purchased were better than expected (surprise), and it required less cognitive effort (trust). Scholars put forward some cognitive evaluation dimensions of different emotions, such as certainty, attention, control, anticipated effort, responsibility, pleasantness, and valence and so on, while each dimension is orthogonal and an independent entity [20]. Therefore, each dimension can be researched separately, and the certainty dimension is chosen in this paper.

In the certainty dimension, emotions can be divided into certainty and uncertainty emotions. The theory of emotional cognitive evaluation found that some emotions were associated with feeling certain. When you experience these kind of emotions, you know what is happening in the current situation and have a feeling of certainty and confidence about what is going to happen in the future. On the contrary, when people experience some other emotions, people have a feeling of uncertainty, and do not understand what is happening in the current situation and are not sure what will happen next [23]. Specifically, such as happy, disgust, angry are certainty emotions; while such as worry, fear, surprise are uncertainty emotions.

In order to study the effects of different negative emotions on the perceived helpfulness of online reviews, this paper chooses emotion "anger" with high certainty and uncertainty emotion "worry" as independent variables. Based on the above, this paper constructs a research model of influencing factors of perceived helpfulness of online reviews as shown in Figure 1, and puts forward relevant hypotheses.

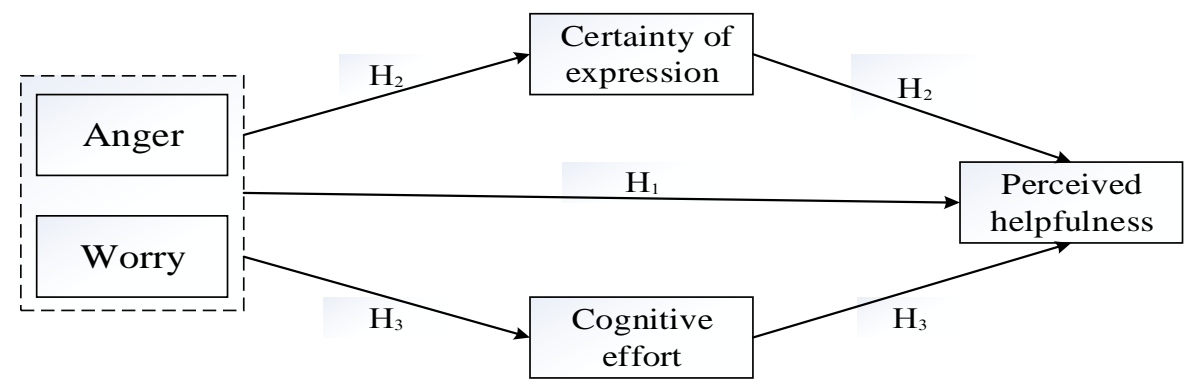

Figure 1: Research framework and conceptual model

\subsection{Research hypotheses}

\subsubsection{Negative emotions and perceived helpfulness}

This study explored from the certainty dimension, choosing two negative emotions: anger and worry which have different certainty and the same valence [24]. Some studies pointed out that although the impact of negative reviews on consumers was greater than that of positive reviews, but it didn't mean the more negative reviews have the more 


\section{Zhu Liu, Jing Liu and Shuang Hao}

helpfulness [25]. Extremely positive or negative reviews may have less impact on consumer purchasing decisions and may be considered useless [26]. The angry mood selected in this paper is the emotion of higher emotional intensity, which expresses the extreme dissatisfaction of consumers on the shopping experience; Such emotions may be perceived as having a strong own emotional tone and personal subjectivity so that such reviews may not evoke consumers empathy, and its perceived helpfulness also has a certain degree of impact which will not help much in consumer decision.

Therefore, we put forward the hypothesis as follows:

H1: In the negative reviews, worry-embedded reviews are perceived to be more helpful than anger-embedded reviews.

\subsubsection{Certainty of expression, cognitive effort and perceived helpfulness}

Certainty evaluation was the perception of the level of affirmation and confidence that a thing may produce, and it was a possible assessment of what will happen [27]. When you feel angry or worried, people are in a negative or sad situation. However, when people feel angry, people are determined about the situation and what will happen. When people feel worried about the future, people have a high degree of uncertainty about the situation they are in and what will happen [20].

According to the emotion dimension and the evaluation tendency which was consistent with the follow-up judgment, researchers thought that the certainty of the task played an intermediary role in the relationship between the certainty dimension of emotion and the influence of the information processing behavior. There is an experiment on the relationship between certainty of emotions and stereotypes. Before the formal experiment, the subjects were asked about the degree of certainty of the task. The test results showed that subjects who experienced certainty emotions reported significantly more certainty than those who experienced uncertainty emotions, and the certainty of the task played an intermediary role in the relationship between the certainty dimension of emotion and the influence of the information processing behavior [28].

Social cognitive theory has recognized that people are motivated to work harder in their cognitive processes when they experience uncertainty [12]. When some scholars described the theory of self-sufficiency, some scholars mentioned that "people would try their best to gain enough confidence in the validity of information"[29]. Festinger suggested that when people feel uncertain about themselves, they will do more social comparisons [30]. Lazarus pointed out that there was an unpredictable risk of negative emotions characterized by uncertainty [24]. To reduce the risk of uncertainty, consumers cautiously handle this type of information [10]. Some researchers claimed that readers will perceive a review as more helpful if they believe the reviewer has expended more cognitive effort in constructing it. This claim is consistent with a broad range of findings in attribution theory and performance estimation, which show that individuals associate effort expenditure with performance across a variety of contexts [31]. In addition, to some extent, writing a helpful review is a challenging task [32]. Thus, a review expresses the uncertainty of consumer emotions, which would allow potential consumers to perceive more cognitive effort and be considered a more helpful review.

Therefore, we put forward the hypothesis as follows:

$\mathrm{H} 2$ : In the negative reviews, certainty expressed through these emotions (anger, worry) mediates the effect of emotions on the perceived helpfulness. 
Effects of Negative Emotions on the Perceived Helpfulness of Online Reviews

H3: In the negative reviews, perceived cognitive effort mediates the differential impact of worry and anger on the perceived helpfulness of reviews.

\section{Research design \\ 4.1. Experimental design and subjects}

In this paper, we use scenario simulation experimental design to test the above assumptions. This experiment selected laptop as a test product. The preparation of online reviews based on the Jingdong, Tmall, Amazon and other shopping sites collected on the laptop's real review information. The dependent variable is the perceived helpfulness, and the mediating variables are the certainty of expression and cognitive efforts. The independent variables we manipulate include two negative emotions: anger and worry. The sample size of this paper is based on the study of Dezhi, Bond and Zhang. We use online survey methods. The advantage of this approach is that its anonymity helps to reduce the bias of social approval. With the help of an online survey company, a total of 102 participants were recruited. After the experiment, we excluded 28 incomplete or obvious rules of the test questionnaire. So the final samples in analysis are 74 .

\subsection{Variable measurement}

(1) Dependent variable. The dependent variables are continuous random variables. The scales of perceived helpfulness (3 items) reference Sen and Lerman's study [33].

(2) Intermediary variables. The scales of certainty of expression (3 items) refer to Tiedens and Linton's study. The scales of cognitive efforts (3 items) reference Huddy et al.'s study [34]. Likert seven-component scale was used to measure dependent and intermediate variables.

(3) Control variables. Pan and Zhang study used review rating to determine the review valence [35]. The review valences in this study are also based on the review rating. The length of the review is determined by the number of words in the review. Control variables also include the respondent's gender, age, education, occupation, monthly income and purchase history.

\subsection{Analysis and discussion}

\subsubsection{Reliability test}

The study uses internal consistency (measured by Cronbach's $\alpha$ ) for reliability analysis. The Cronbach alpha coefficient of perceived helpfulness, certainty of expression, cognitive efforts respectively are $0.904,0.768$ and 0.924 . The Cronbach $\alpha$-values of the variables in this study are all above 0.7 . Therefore, the internal validity of the display is acceptable.

\subsubsection{Hypothesis test}

(1) Direct effect test. A repeated-measure ANCOVA was performed to examine the difference in perceived helpfulness across these reviews. Emotional condition was entered as a within-subject factor, and the counterbalancing of the three reviews was entered as a covariate. In line with H1, pairwise comparisons revealed that the difference in perceived helpfulness between worry and anger conditions was significant ( $M=4.9234$ vs 5.1351, $\mathrm{t}=-2.115, \mathrm{P}<0.05)$. Thus, reviews containing worry were considered more helpful than those containing anger, despite having the same objective content. 


\section{Zhu Liu, Jing Liu and Shuang Hao}

(2) Mediation Effect.

(a) Some mathematical tools about the Mediation Effect Test

This article draws on Judd et al. mediation effect test method [36]. In this study, perceived helpfulness is dependent variable, and emotions (anger and worry) are independent variables. Y1 and Y2 are the scores of dependent variables under two emotions, and $\mathrm{X} 1$ and $\mathrm{X} 2$ are the scores of mediation variables under the condition of two independent variables.

The first step is to establish the function of dependent variable (Y1, Y2) and mediation variables $(\mathrm{X} 1, \mathrm{X} 2)$ respectively.

$$
\begin{aligned}
& Y_{1} i=\delta_{10}+\delta_{11} X_{1} i+\varepsilon_{1} i, \\
& Y_{2} i=\delta_{20}+\delta_{22} X_{2} i+\varepsilon_{2} i ;
\end{aligned}
$$

The models of variables $\mathrm{X} 1$ and $\mathrm{X} 2$ are respectively:X1i $=\lambda_{10}+\varepsilon_{1 i}, X_{2 i}=\lambda_{20}+\varepsilon_{2 i}$.

The second step, first of all, we calculate the mean difference of intermediary variables and dependent variables in two cases.

$$
\begin{aligned}
& X_{\mathrm{D}} i=X_{2} i-X_{1} i=\left(\lambda_{20}-\lambda_{10}\right)+\left(\varepsilon_{2} i-\varepsilon_{1 i}\right), \\
& Y_{\mathrm{D}} i=Y_{2} i-Y_{1} i=\left(\delta_{20}-\delta_{10}\right)+\delta_{22} X_{2} i-\delta_{11} X_{1} i+\left(\varepsilon_{2} i-\varepsilon_{1} i\right) ;
\end{aligned}
$$

Next, we calculate the mean sum of the mediator variables in both cases.

$$
X_{\mathrm{S}} i=X_{2} i+X_{1} i=\left(\lambda_{20+} \lambda_{10}\right)+\left(\varepsilon_{2} i+\varepsilon_{1 i}\right) ;
$$

Last, according to the study of Judd et al. (2001), moderation had two equivalent definitions: (a) The X:Y relationship depends on condition, and (b) the magnitude of the treatment effect depends on the value of $X$ (in this case, assuming one common value).

In their study, they relaxed the assumption that $X_{1} i=X_{2} i$, continuing to allow unequal within-condition slopes, so the model can specify in equation as follows:

$$
Y_{\mathrm{D}} i=Y_{2} i-Y_{1} i=\left(\delta_{20}-\delta_{10}\right)+\delta_{22} X_{2} i-\delta_{11} X_{1} i+\left(\varepsilon_{2} i-\varepsilon_{1} i\right) \text {; }
$$

In their research, they mentioned that this equation can be re-expressed in terms of the corresponding difference and the sum of the two $X$ variables. This amounted to a $45^{\circ}$ rotation of the two original $\mathrm{x}$-axes. Therefore, the equation can be equivalently expressed as follows:

$$
Y_{\mathrm{D}} i=\left(\delta_{20}-\delta_{10}\right)+\frac{\delta 22-\delta 11}{2} X_{\mathrm{S}} i+\frac{\delta 22+\delta 11}{2} X_{D i}+\left(\varepsilon_{2} i-\varepsilon_{1} i\right)
$$

where $X_{\mathrm{S}} i=X_{2} i+X_{1} i, X_{\mathrm{D}} i=X_{2} i-X_{1} i$.

Having discussed this model, they estimated it. One can estimated a single regression model in which the difference in the two Y scores for each unit was regressed on two predictors, the sum of that unit's $X$ scores and the difference in that unit's $X$ scores (with the $\mathrm{Y}$ and $\mathrm{X}$ differences taken in the same direction).

$Y_{\mathrm{D}} i=d_{0}+d_{1} X_{\mathrm{S}} i+d_{2} X_{\mathrm{D}} i+\mathrm{e}_{\mathrm{YD} i}\left(X_{\mathrm{S}} i\right.$ is the centered mean sum);

In above equation, first, the slope $d_{1}$ for the sum $X_{S} i\left(=X_{2} i+X_{1} i\right)$ estimates 
Effects of Negative Emotions on the Perceived Helpfulness of Online Reviews

$\left(\delta_{22}-\delta_{11}\right) / 2$, half of the difference of the within-condition slopes for the mediator variables $\mathrm{X}$, and indicates moderation of the treatment effect in $\mathrm{Y}$ depending on the level of the $\mathrm{X}$ sum. Second, the slope $d_{2}$ for the difference $X_{\mathrm{D}} i\left(=X_{2} i-X_{1} i\right)$ estimates $\left(\delta_{22}+\delta_{11}\right) / 2$, the average of the two within-condition slopes for the mediator variables $\mathrm{X}$, and indicates mediation of the treatment effect in $\mathrm{Y}$, assuming a mean difference between the two $X_{\mathrm{S}}$. Third, the intercept $d_{0}$ estimates $\delta_{20}-\delta_{10}$, (assuming $X_{\mathrm{S}} i$ centered).

(b) Mediation Effect Test

Based on the above mediation effect test process, this article needs to be three times regression. The test results are as follows:

Before regression, we use paired sample $\mathrm{T}$ test to compare the two mediation variables under the two conditions. Under certainty of expression: $\left(M_{1}=3.4955\right.$ vs 3.2523, $\mathrm{t}=2.059, \mathrm{p}<0.05)$;Under cognitive efforts: $\left(\mathrm{M}_{2}=4.1351\right.$ vs $4.3784, \mathrm{t}=-2.044$, $\mathrm{p}<0.05)$.

In the first regression, the mediators of each group had a significant effect on the perceived helpfulness of each group $(\mathrm{P}<0.05$. The regression results are shown in Table 1 and Table 2.

Table 1: Certainty of expression regression one

\begin{tabular}{ccccc}
\hline $\begin{array}{c}\text { Certainty of } \\
\text { expression }\end{array}$ & $\mathrm{B}$ & $\mathrm{R} 2$ & $\mathrm{~F}$ & Sig. \\
\hline angry & 0.365 & 0.105 & 9.554 & 0.003 \\
worry & 0.330 & 0.097 & 8.834 & 0.004 \\
\hline
\end{tabular}

Table 2: Cognitive effort regression one

\begin{tabular}{ccccc}
\hline Cognitive effort & B & R2 & F & Sig. \\
\hline angry & 0.630 & 0.409 & 51.463 & 0.000 \\
worry & 0.633 & 0.437 & 57.605 & 0.000 \\
\hline
\end{tabular}

In the second regression, the mean difference of mediation variable (certainty of expression) have a significant effect on the mean value of perceived helpfulness $(B=$ $0.338, \mathrm{t}=3.714, \mathrm{P}<0.001$ ); and the mean difference of mediation variable(cognitive effort) have a significant effect on the mean value of perceived helpfulness $(B=0.522, t=6.677$, $\mathrm{P}<0.001$ ). But the mean sum of mediation variable (certainty of expression) have no significant effect on the mean value of perceived helpfulness $(B=-0.059, t=-1.407, P>$ 0.05 ); the mean sum of mediation variable (cognitive effort) have no significant effect on the mean value of perceived helpfulness $(B=-0.027, t=-0.803, P>0.05)$. The regression results are shown in Table 3 and Table 4. 
Zhu Liu, Jing Liu and Shuang Hao

Table 3: Certainty of expression regression two

\begin{tabular}{ccccc}
\hline $\begin{array}{c}\text { Certainty of } \\
\text { expression }\end{array}$ & $\mathrm{B}$ & $\mathrm{R} 2$ & $\mathrm{~F}$ & Sig. \\
\hline constant & 0.270 & & & 0.370 \\
$\mathrm{C} 1$ & 0.338 & 0.159 & 7.920 & 0.000 \\
$\mathrm{C} 2$ & -0.059 & & & 0.164 \\
\hline
\end{tabular}

Table 4: Cognitive effort regression two

\begin{tabular}{ccccc}
\hline $\begin{array}{c}\text { Cognitive } \\
\text { effort }\end{array}$ & B & R2 & F & Sig. \\
\hline constant & 0.145 & & & 0.629 \\
E1 & 0.522 & 0.370 & 22.412 & 0.000 \\
E2 & -0.027 & & & 0.425 \\
\hline
\end{tabular}

In order to aid interpretation, we need to make the third regression. As previously explained, we re-estimate this model after centering the sum variable. The mean sum centered of mediation variables (certainty of expression) have no significant effect on the mean value of perceived helpfulness

$$
(B=-0.059, \mathrm{t}=-1.407, \mathrm{P}=0.164) ;
$$

and the mean sum centered of mediation variables (cognitive effort) have no significant effect on the mean value of perceived helpfulness $(B=-0.027, t=-0.803, P=0.425)$. Therefore, criteria for mediation were met. Moreover, the mediation variable (certainty of expression) coefficient of the intercept were not significant

$$
(\mathrm{B}=-0.130, \mathrm{t}=-1.372, \mathrm{P}=0.174) \text {; }
$$

and the mediation variable (cognitive effort) coefficient of the intercept were not significant $(B=-0.085, t=-1.036, P=0.304)$, indicating full mediation. The results are shown in Table 6. Taken together, these results on perceptions of review helpfulness were mediated by cognitive effort and certainty of expression.

Table 5: Certainty of expression regression three

\begin{tabular}{ccccc}
\hline $\begin{array}{c}\text { Certainty of } \\
\text { expression }\end{array}$ & $\mathrm{B}$ & $\mathrm{R} 2$ & $\mathrm{~F}$ & $\mathrm{Sig}$. \\
\hline constant & -0.130 & & & 0.174 \\
C1 & 0.338 & 0.159 & 7.920 & 0.000 \\
C3 & -0.059 & & & 0.164 \\
\hline
\end{tabular}


Effects of Negative Emotions on the Perceived Helpfulness of Online Reviews

Table 6: Cognitive effort regression three

\begin{tabular}{ccccc}
\hline $\begin{array}{c}\text { Cognitive } \\
\text { effort }\end{array}$ & B & R2 & F & Sig. \\
\hline constant & -0.085 & & & 0.304 \\
E1 & 0.522 & 0.370 & 22.412 & 0.000 \\
E3 & -0.027 & & & 0.425 \\
\hline
\end{tabular}

\section{Conclusion and discussion \\ 5.1. Conclusion}

Based on the theory of emotional cognitive evaluation, this paper constructs a mechanism model of the impact of negative emotions on perceived helpfulness of online reviews. We use experimental research methods of scenario simulation. Test results found that: In the negative reviews, worry-embedded reviews are perceived to be more helpful than angerembedded reviews. In the negative reviews, certainty expressed through these emotions mediates the effect of emotions on the perceived helpfulness, and perceived cognitive effort mediates the differential impact of worry and anger on the perceived helpfulness of reviews.

\subsection{The theoretical and practical significance}

The theoretical significance of this paper includes three aspects: First, the use of emotion in the perception of helpful information provides a new research idea and theoretical perspective for the study of the application of emotion in the field of information management. Within the IS field, however, affective issues are often overlooked [37]. For example, emotional components play no direct role in such prominent conceptual frameworks as the technology acceptance model, media richness theory, and tasktechnology fit theory $[38,39,40]$. Within IS, a few scholars have explored the distinct roles of emotions in technology acceptance [6], and online trust [41]. This article explored the important role that specific emotions played in reviews, and confirmed the different effects of different emotions in the reviews on the reader's perception. Consumers' perceptions of emotions in reviews come from searching for product information. Therefore, this research expands the use of emotions in the field of information management to a certain extent.

Second, we start from the different emotions of consumers and go deep into specific texts of reviews to enrich the research on the structure of reviews. In the past, any scholars discussed the impact of online reviews on perceived helpfulness mainly from the quality of the reviews content, such as Pan and Zhang, Korfiatis, et.al. They less researched on the helpfulness of the textual features of the content of the reviews, especially from a specific emotional point of view. This article studied the influence of specific emotional vocabulary on the perception of helpfulness in the review. The results show that there is a big difference in consumers' perception of reviews with different emotion words. And perceived helpfulness also was influenced by the certainty expressed by the review and the perceived cognitive effort of the readers. Therefore, this study enriches the research on the content structure of online reviews.

Finally, starting from the deterministic dimension of emotion, we introduce 


\section{Zhu Liu, Jing Liu and Shuang Hao}

mediation variables to study the role of emotion in consumer behavior, which is a supplement to the concept and structure of emotions. Scholarship in this area tends to focus on the role of emotion within the individual, overlooking the critical interpersonal purposes that emotions often serve [42]. The emotions (positive or negative) that consumers express in reviews can have an effect on the potential consumer reading or understanding the reviews. Finally, it can affect the consumer's purchasing decision. Therefore, the importance of the role of emotion in consumer behavior cannot be ignored.

The management implications of this article: First, this result can help consumers quickly and effectively identify helpful review information. Potential consumers can rapidly judge the reliability of review information based on the expression of consumer sentiment in different negative reviews, and reduce the purchase risk and improve shopping satisfaction.

Second, for sellers, it can help them improve their marketing strategies and promote the sale of their products. Sellers should pay attention to consumers' reviews on postshopping emotions, and consumers should be encouraged to express their emotions when they write reviews. Sellers encourage consumers to express their feelings to a certain extent, which can promote the sale of products.

Finally, for the e-commerce platform, it has some reference to the improvement of platform functions. E-commerce platform managers can set a certain guideline when consumers write reviews. So platform managers can prompt consumers to post or choose the emotions after shopping. The platform can also quickly and accurately judge its helpfulness based on the emotional strength of negative reviews. At the same time, the platform can learn from the presentation of Da Zong Dian Ping's online reviews, and put these helpful reviews in front of the comment bar, which can provide some convenience for consumers.

\subsection{Research limitations}

First of all, helpful research is only conducted on several specific emotions in the negative reviews, and other emotions may also have some impact on perceived helpfulness. Therefore, the effects of other emotions can be explored in the future, such as disappointment, surprise and so on. Second, although the sample size of this paper is similar to previous studies, but it does not exclude other findings obtained after expanding the sample size. Therefore, further research can be carried out by expanding the sample size in the future.

\section{REFERENCES}

1. CNNIC. China online shopping market research report in 2015. http://www.cnnic.net.cn/hlwfzyj/hlwxzbg/dzswbg/201606/P02016072152697563227 3.pdf, (2016).

2. C.Dellarocas, The Digitization of word of mouth: promise and challenges of online feedback mechanisms, Social Science Electronic Publishing, 49(10) (2003) 14071424.

3. Q.Jones, G.Ravid and S.Rafaeli, Information overload and the message dynamics of online interaction spaces: a theoretical model and empirical exploration, Information Systems Research, 15(2) (2004) 194-210.

4. J.Arndt, Role of product-related conversations in the diffusion of a new product, 
Effects of Negative Emotions on the Perceived Helpfulness of Online Reviews

Journal of Marketing Research, 4(3) (1967) 291-295.

5. R.Ahluwalia, R.E.Burnkrant and H.R.Unnava, Consumer response to negative publicity: the moderating role of commitment, Journal of Marketing Research, 37(2) (2000) 203-214.

6. T.Verhagen, A.Nauta and F.Feldberg, Negative online word-of-mouth: Behavioral indicator or emotional release? Computers in Humans Behavior, 29(4) (2013) 14301440.

7. D.Yin, S.D.Bond and H.Zhang, Anxious or angry? effects of discrete emotions on the perceived helpfulness of online reviews, Mis Quarterly, 38(2014) 539-560.

8. C.J.White, The impact of emotions on service quality, satisfaction, and positive wordof-mouth intentions over time, Journal of Marketing Management, 26(5) (2010) 381394.

9. R.A.Westbrook, Product/consumption-based affective responses and post purchase processes, Journal of Marketing Research, 24(3) (1987) 258-270.

10. R.Raghunathan and M.T.Pham, All negative moods are not equal: motivational influences of anxiety and sadness on decision making, Organ Behave Hum Decis Process, 79(1) (1999) 56.

11. S.Cai, Z.Qin, C.Li et al., The impact of affective intensity of negative online comments on usability, Management Comments, 29(2) (2017) 79-86.

12. X.Huang, H.Yu and Z.Chen, Consumers' choice in emotional confirmation and uncertainty: the application of discount heuristic, Journal of Marketing Science, 6 (2) (2010) 14-31.

13. J.A.Chevalier and D.Mayzlin, The effect of word of mouth on sales: online book reviews, Journal of Marketing Research, 43(3) (2006) 345-354.

14. C.Forman, A.Ghose and B.Wiesenfeld, Examining the relationship between reviews and sales: the role of reviewer identity disclosure in electronic markets, Information Systems Research, 19(3) (2008) 291-313.

15. H.S.Bansal and P.A.Voyer, Word-of-mouth processes within a services purchase decision context, Journal of Service Research, 3(2) (2000) 166-177.

16. Y.H.Cheng and H.Y.Ho, Social influence's impact on reader perceptions of online reviews, Journal of Business Research, 68(4) (2015) 883-887.

17. L.Connors, S.M.Mudambi and D.Schuff, Is it the review or the reviewer? a multimethod approach to determine the antecedents of online review helpfulness, Hawaii International Conference on System Sciences. IEEE Computer Society, (2011) 1-10.

18. D.A.S.Kempf and K.M.Palan, The effects of gender and argument strength on the processing of word-of-mouth communication, Academy of Marketing Studies Journal, 10(1) (2006).

19. S.N.Ahmad and M.Laroche, How do expressed emotions affect the helpfulness of a product review? evidence from reviews using latent semantic analysis, International Journal of Electronic Commerce, 20(1) (2016) 76-111.

20. P.Ellsworth and C.Smith, Patterns of cognitive evaluation in emotion, Journal of Personality and Social Psychology, 48(4) (1985) 813-838.

21. I.J.Roseman, Cognitive determinants of emotion: a structural theory, Review of Personality and Social Psychology, 5 (1984) 11-36.

22. I.J.Roseman and C.A.Smith, Evaluation theory: overview, assumptions, varieties, controversies, in Evaluation Processes in Emotion: Theory, Methods, Research, K. R. 
Zhu Liu, Jing Liu and Shuang Hao

Scherer, A. Schorr and T. Johnstone (eds.), New York: Oxford University Press, pp. (2001) 3-19.

23. P.C.Ellsworth and C.A.Smith, From evaluation to emotion: Differences among unpleasant feelings, Motivation \& Emotion, 12(3) (1988) 271-302.

24. R.S.Lazarus, Emotion and adaptation, New York: Oxford University Press 1991.

25. Q.Cao, W.Duan and Q.Gan, Exploring determinants of voting for the "helpfulness" of online user reviews: A text mining approach, Decision Support Systems, 50 (2) (2011) 511-521.

26. N.Korfiatis, E.García-Bariocanal and S.Sánchez-Alonso, Evaluating content quality and helpfulness of online product reviews: The interplay of review helpfulness vs. review content, Electronic Commerce Research \& Applications, 11(3) (2012) 205217.

27. I.Roseman, R.P.Abelson and M.F.Ewing, Emotion and political cognition: Emotional appeals. In R.Lau and D.O.Sears (eds), Political communications. Political Cognition. Nineteenth Annual Carnegie Symposium on Cognition. Mahway; NJ: Lawrence Erlbaum, (1986) 279-296.

28. L.Z.Tiedens and S.Linton, Judgment under emotional certainty and uncertainty: The effects of specific emotions on information processing. J Pers Soc Psychol, 81(6) (2001) 973-88.

29. A.H.Eagly and S.Chaiken, The psychology of attitudes, Harcourt Brace Jovanovich College Publishers, (1993).

30. L.Festinger, A theory of social comparison processes, Human Relations, 7(7) (1954) 117-140.

31. E.A.Skinner, M.Chapman and P.B.Baltes, Control, means-ends, and agency beliefs: A new conceptualization and its measurement during childhood, Journal of Personality \& Social Psychology, 54(1) (1988) 117-133.

32. S.M.Mudambi and D.Schuff, What makes a helpful online review? a study of customer reviews on amazon.com, Mis Quarterly, 34(1) (2010) 185-200.

33. S.Sen and D.Lerman, Why are you telling me this? An examination into negative consumer reviews on the Web, Journal of Interactive Marketing, 21(4) (2007) 76-94.

34. L.Huddy, S.Feldman and E.Cassese, On the distinct political effects of anxiety and anger, The Affect Effect: Dynamics of Emotion in Political Thinking and Behavior, A. Crigler,M. Mackuen, G.E.Marcus, and W.R.Neuman (eds.), Chicago: University of Chicago Press, (2007) 202-230.

35. Y.Pan and J.Q.Zhang, Born unequal: a study of the helpfulness of user-generated product reviews, Journal of Retailing, 87(4) (2011) 598-612.

36. C.M.Judd, D.A.Kenny and G.H.Mcclelland, Estimating and testing mediation and moderation in within-subject designs, Psychological Methods, 6(2) (2001) 115.

37. H.Sun and P.Zhang, The role of affect in information systems research, in HumanComputer Interaction and Management Information Systems: Foundations, P.Zhang \& D.F.Galletta (eds.), Armonk, NY: M.E. Sharpe, pp.295-329.

38. D.L.Goodhue and R.L.Thompson, Task-technology fit and individual performance, Mis Quarterly, 19(2) (1995) 213-236.

39. F.D.Davis, Perceived helpfulness, perceived ease of use, and user acceptance of information technology, Mis Quarterly, 13(3) (1989) 319-340.

40. R.L.Daft, R.H.Lengel and L.K.Trevino, Message equivocality, media selection, and 
Effects of Negative Emotions on the Perceived Helpfulness of Online Reviews

manager performance: implications for information systems, Mis Quarterly, 11(3) (1987) 355-366.

41. Y.Hwang and D.J.Kim, Customer self-service systems: The effects of perceived Web quality with service contents on enjoyment, anxiety, and e-trust, Decision Support Systems, 43(3) (2007) 746-760.

42. G.A.V.Kleef, The emerging view of emotion as social information, Social \& Personality Psychology Compass, 4(5) (2010) 331-343. 